\title{
ALGAL GROWTH AND NUTRIENTS REMOVAL AS AFFECTED BY NITROGEN SOURCE
}

\author{
El-Kassas, H. I. ${ }^{(1)}$; El-Sayed, A .B. ${ }^{(2)}$; Mostafa, Maryam, M. $^{(3)}$ \\ and Reda, Marwa, $M$.
}

1) Institute of Environmental Studies and Research, Ain Shams Univ. 2) Algal Biotechnology Unit, Fertilization Technology Dep.; National Research Centre. 3) Central Lab. for Environmental Quality Monitoring, National Water Research Center

\begin{abstract}
The current work was performed aiming at the determine growth line of two different algae species under two different nitrogen sources which in turn affect some nutrients removing from growth medium as an earliest experiment for future use of algae in agricultural drainage water treatment. Two different algae species were tested in the current study to determine their growth potential as they grown with their original growth media and under replacement of original nitrogen source. The first alga was Chlorella vulgaris belonging to Chlorophyta, while the second is Spirulina platensis belonging to Cyanophyta. BG-II growth medium was used for the first one and Zarrouk growth medium was implemented to the second. The original nitrogen source of both media was substituted by low price form as urea by the same equivalent. Daily determination of biomass was performed beside nutrients removal.

The results showed that nitrate stimulated growth of both Chlorella and Spirulina algae and urea seems to be the proper in Chlorella growth rather than Spirulina. Maximum nutrient removal or absorption was observed during the early growth period (48 hours). Chlorella vulgaris was found to be more bio-removal agent rather than Spirulina platensis.

Keywords: algae; nitrogen source; dry weight; Nutrients Removal.
\end{abstract}


J. Environ. Sci.

Institute of Environmental Studies and Research - Ain Shams University

\section{INTRODUCTION}

Among the most critical variables in algal production, water and nutrients were considered. Algae can be grown in both fresh water and seawater depending on species and natural habitat, but nutrient costs can be substantial. The main nutritional requirements for algal growth are nitrogen, phosphorous, potassium and a number of micronutrients. Algae consume nutrients along with $\mathrm{CO}_{2}$ and produce biomass via photosynthesis. Various combinations of fertilizers may be used including common field crop NPK fertilizer, but the associated costs can sometimes exceed the value of the final algae products (El-Sayed et al., 2001 and Dalrymple et al., 2013).

Microalgae are expensive in production cost especially in small units due to carbon and electric power (El-Sayed, 2007). Thus, use of commercial fertilizers (El-Sayed et al., 2001) as well as food industrial wastes (El-Sayed et al., 2012) markedly downed the mineral nutrition cost of mass produced algae mainly carbon. Carbon dioxide is a key of photosynthetic processes required mainly light and algal growth might be limited under condition of carbon and light deficiency.

Mineral nutrition of mass algal culture in term of carbon represented the main figure in concern production costs, where algal skeleton composed of more than $50 \%$ carbon and algae fix carbon dioxide by about 40 folds than higher plants. On the other hand, only $15 \%$ of the fed carbon dioxide to algae grown in laboratory closed system was utilized by algae and the remainder was return again to the outer space (El-Sayed et al., 2015). Using of organic carbon allowing the fully utilization of the given carbon which in turn safe 
environment and minimizing production cost (El-Sayed et al., 2011 and Battah et al., 2013). Particularly among various nutritional factors, nitrogen is considered one of the most critical nutrients for algal growth, since it is a constituent in all structural and functional proteins such as peptides, enzymes, chlorophylls, energy transfer molecules، and genetic materials (Cai et al., 2013). Concentration of nitrogen in culture medium consider ably affects both cell growth rate and biochemical compositions of microalgae (Wang et al., 2013).

The major source of organic waste is animal manure, but there are considerable amounts of organic waste originating from the food industry such as dairy, olive-oil mill, and winery. There are various biological, physicochemical, and mechanical methods to treat all of these wastes and wastewater (Imbeah, 1998; Burton and Turner, 2003; Burton, 2007; and Bernet and Beline, 2009). Moreover, Chlorella vulgaris was grown successfully in corn steam liquor effluent in completely free nutrients growth medium (Battah et al., 2013 and El-Sayed et al., 2015).

The highest Spirulina cell density was obtained in the medium that contained $16.3 \%$ waste leachate and $83.7 \%$ Zarrouk medium. However, the authors judged that a medium that contained $33.3 \%$ of waste leachate and 66.7\% Zarrouk medium had the greatest practical benefit. Higher output rates were obtained by the addition of $\mathrm{NaHCO}_{3}$, nitrate and phosphate. The addition of 2.0 g. $1^{-1} \mathrm{NaHCO}_{3}$ gave three times output higher than that obtained without $\mathrm{NaHCO}_{3}$ and the addition of nitrate and phosphate gave around $100 \%$ and $50 \%$ higher output rates, respectively. In outdoor experiments, in which the only nutrients added to the leachate were $\mathrm{NaNO}_{3}$ 
and $\mathrm{NaHCO}_{3}$, the highest production rate amounted to14 g.m $\mathrm{m}^{-2} \cdot \mathrm{d}^{-1}$ (Mitchell and Richmond, 1988).

Further study by Blier et al. (1995) showed that Phormidium bohneri its maximum biomass concentration and growth rate in the more diluted effluent (30 mg. $\mathrm{l}^{-1} \cdot \mathrm{d}^{-1} \mathrm{~N}-\mathrm{NH}_{3}$ ) rather than those of grown at 40 and $50 \mathrm{mg} \mathrm{N} \mathrm{NH} \cdot \mathrm{l}^{-1}$. Biomass concentration amounted to $565 \mathrm{mg} . \mathrm{l}^{-1}$ after 16 days of cultivation. Ammonia removal $\left(2.9-3.1 \mathrm{mg} \mathrm{N}-\mathrm{NH}_{3} \cdot \mathrm{l}^{-1} \cdot \mathrm{d}^{-1}\right)$ was almost the same for all dilutions, but the highest removal of phosphorus (4.9 mg. $\mathrm{l}^{-1} \cdot \mathrm{d}^{-1} \mathrm{PO}_{4}^{-3}$ ) was achieved in the least diluted effluent.

\section{MATERIALS AND METHODS}

Algae and Growth Condition: Two different algal species were used in the current study to meet the investigation concept in concern drastic bio-removal of saline nutrients by algae to re-use it in agricultural purposes. The first was the green alga Chlorella vulgaris Beijerinck (NRC) belongs to Chlorophyta, that grow well in most Egyptian habitat with low salt concentration, while the second was the blue-green alga Spirulina platensis ( Gomont) Geitler belonging to Cyanophyta which found in relatively high saline water. Both algae are widely varied in their salt margin mainly sodium concentration. Both of them were massively produced in Algal Biotechnology Unit, National Research Centre, Cairo, Egypt.

Nutrients Solution: Two different types of macronutrient solutions were used due to the behavior of algal growth in concern chemical composition as well as nutrients content. For Chlorella growth, BG-II medium (Stainer et al., 1971) was used, while Zarrouk medium (Zarrouk, 1966) was used in 
Spirulina case. The main variation of both growth media is the high sodium content of Zarrouk medium that reaches $18.6 \mathrm{~g} . \mathrm{l}^{-1}$ in bicarbonate form. As for micronutrients, A5 micronutrients mixture was used at $1 \mathrm{ml}^{-1}{ }^{-1}$ for both algae. For all of these, stock solutions were made at the first time and fresh preparation was performed by in time dilution with bi-distilled water.

Indoor Growth Unit: For algal lab scale experiments, fully light transparent Plexi-glass columns (100 cm length x $7 \mathrm{~cm}$ diameter x $5 \mathrm{~mm}$-in thickness) containing 2.5L of algal growth medium were used (El-Sayed, 1999). Continuous illumination was provided from white florescent lamps reflexing from one side to give $120 \mu$.e of light intensity. Aeration and turbulence were carried out by free oil compressed air from the lower hold throughout $6 \mathrm{~mm}$ polyethylene hose. Experiments were performed at room temperature.

\section{Experiment:}

Effect of Nitrogen Sources On Algal Growth: The experiment was performed aiming to determine the effect of nitrogen source on growth dry weight and nutrients removal by the grown algae. Nitrogen source of the original growth medium $\left(\mathrm{NaNO}_{3}\right)$ was substituted by the same equivalent nitrogen content on urea form (17.6 mM N). Accordingly, 0.53 and 0.88 g. $1^{-1}$ of urea were used with modified BG-II and Zarrouk-medium; respectively.

Growth Parameter: During the whole cultivation period, periodically measuring of algal dry weight was performed (48 hours). For dry weight determination, $5 \mathrm{ml}$ from each replicate were separately filtered over a preweighted Whatman sterile membrane filters (pore size $0.45 \mu \mathrm{m}, 0.47 \mathrm{~mm}$ in diameter and white grade). After filtration, filters were left to dry for 30 minutes at $105^{\circ} \mathrm{C}$ circulated oven, kept over anhydrous calcium chloride till 
room temperature and then re-weighted. The difference between weights monitored the net dry weight of the grown alga within a defined sampling time. Dry weight was calculated as $g .1^{-1}$ expressing the net accumulated algal biomass within sampling period.

Nutrients Removing By Grown Algae: Nutrient removal was also determined following each experiment. Nutrients removal in concern N, P, $\mathrm{K}$, $\mathrm{Na}$ and $\mathrm{Ca}$ by the grown algae was determined during the completely experimental duration. It was done by filtering $25 \mathrm{ml}$ of algal broth over membrane filter $(0.45 \mu \mathrm{m})$, The precipitated biomass over membrane filter was washed by $0.1 \mathrm{~N} \mathrm{HCl}$ to remove all outer nutrients of algal cells. The received volume was then completed to $50 \mathrm{ml}$. Nutrients concentration was then determined by the adopted methods of (Chapman and Pratt, 1974).

\section{RESULTS AND DISCUSSION}

Effect of Nitrogen Sources on Alga Dry Weight Accumulation: When algae were grown under different nitrogen sources, two comparison ways could be considered in this action. The first is nitrogen source, while the second is the examined algae. As shown in Fig. 1; dry weight of Chlorella vulgaris was markedly increased under urea nitrogen and the net obtained biomass were 0.791 and 1.105 g. $1^{-1}$ for nitrate and urea nitrogen grown alga, respectively. 

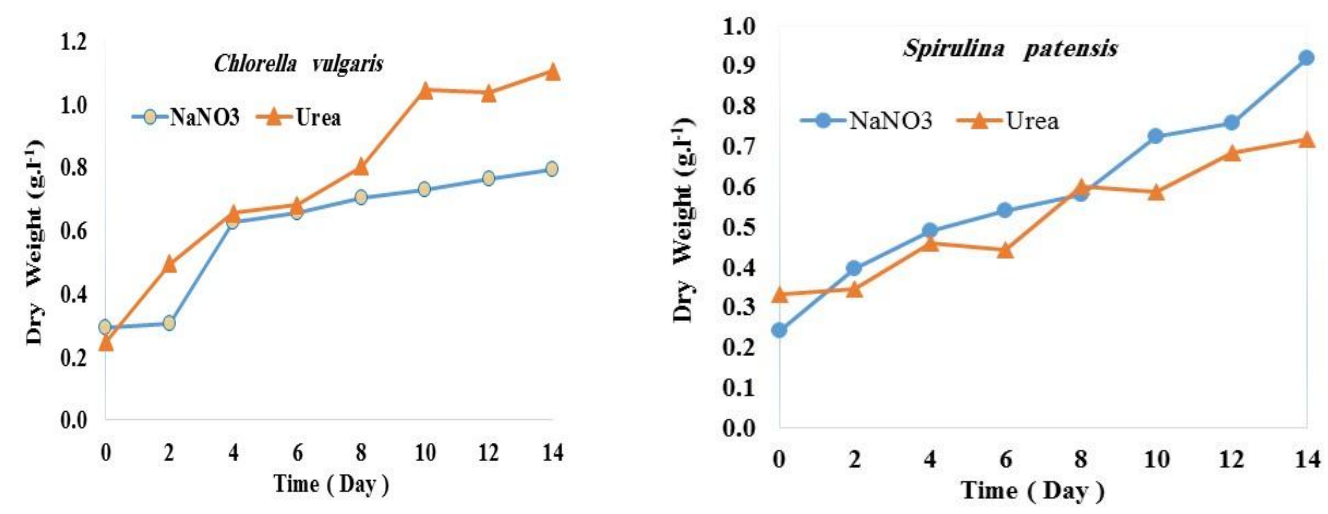

Fig. 1. Growth dry weight (g. $\left.1^{-1}\right)$ of Chlorella vulgaris Beijerinck (NRC) and Spirulina platensis (Gomont) Geitler as affected by nitrogen source.

In the case of Spirulina platensis growth dry weight inhibition under urea grown was markedly observed compared with those of nitrate cultures and the net biomass were recorded as 0.918 and $0.717 \mathrm{~g} . \mathrm{l}^{-1}$ for nitrate and urea grown alga, respectively. Dry weight decline was more progresses in urea grown cultures as compared with nitrate. This observation could attribute to the lack of sodium ions in urea grown cultures and the acidic profile of urea grown cultures. Furthermore, the original Spirulina platensis growth medium tended to be alkaline reaction.

It was early reported that urea surpasses nitrate nitrogen for Chlorella vulgaris growth, where urea supported Chlorella growth media by both nitrogen and carbon sources. These results indicate that the preference for nitrogen source and the ability of nitrogen utilization are different from species to species. Thus, the growth enhancement of Chlorella vulgaris under urea nitrogen makes it a promising bio-reminder tool in in future use by 
consuming the maximum content of sodium ions that present the main salinity causes. The same results were found by (El-Sayed, 1999) who found that urea metabolism decreases the alkalinity effect of algal growth, which in turn affected Spirulina platensis growth that required alkaline growth media reaction. In addition, nitrate metabolism shifted algal growth medium to alkaline margin due to the liberated sodium ions.

Kalla and Khan (2016) reported that the growth was significantly affected; maximum algal density was observed in control culture (1.5 g. l $^{-1}$ $\mathrm{NaNO}_{3}$ ). The growth showed decrease as $\mathrm{NaNO}_{3}$ in medium was reduced from $0.75,0.375$ and 0.0 g.l ${ }^{-1} \mathrm{NaNO}_{3}$ and $\mathrm{NaNO}_{3}$ replaced by $\mathrm{NaCl}$. An increasing trend was observed from zero days to $21^{\text {st }}$ day after which a stationary phase was attained on $28^{\text {th }}$ day .

Dziosa and Makowska (2016) reported that the process of new cell formation of Chlorella SP. was increasingly associated with old cell death and autolysis. After 22 days of algae culture, the depletion in the content of phosphorous was observed. It caused an inhibition of nitrogen assimilation within the cells and decrease in optical density.

\section{Effect of Nitrogen Sources on Media Reaction (Ph):}

Media reaction $(\mathrm{pH})$ at the early growth period severely acute growth potential, however the next growth period could be serve as a growth profile. In natural, Chlorella vulgaris medium seems to be neutral $(\mathrm{pH}=7)$. On the other hand, Spirulina platensis is alkaline growth medium $(\mathrm{pH}=9-11)$. 


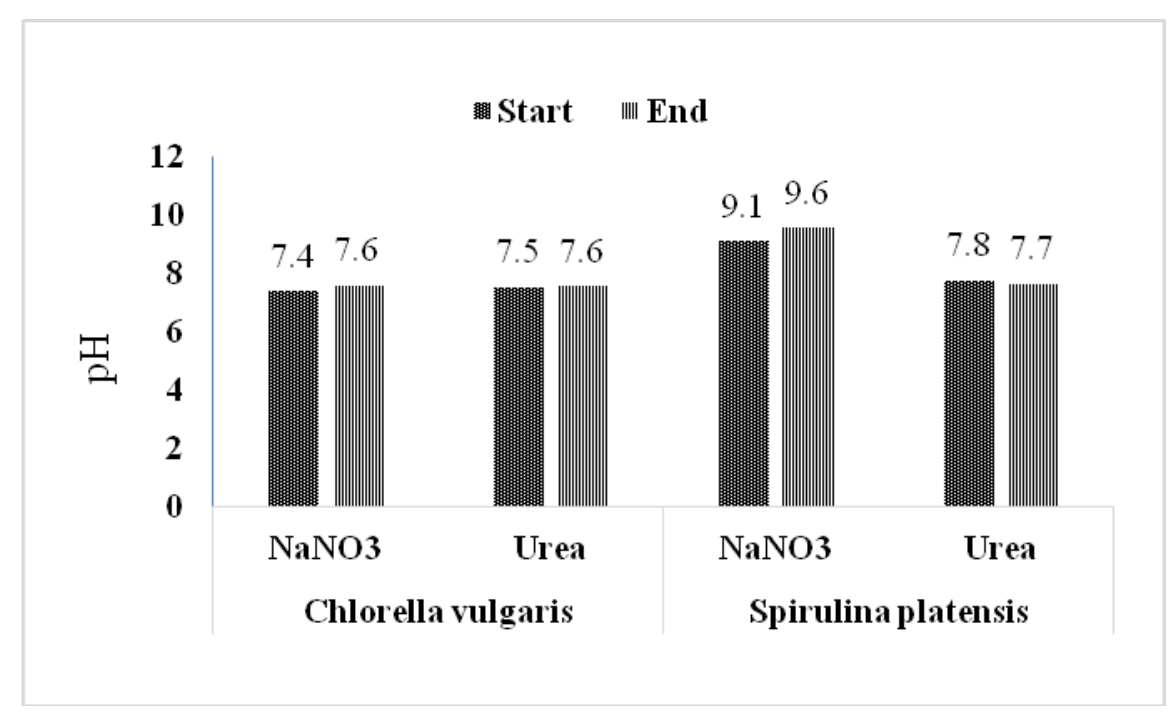

Fig. 2. Media reaction ( $\mathrm{pH})$ of Chlorella vulgaris Beijerinck (NRC) and Spirulina platensis (Gomont) Geitler as affected by nitrogen source.

As shown in Fig. 2, when urea replaced nitrate as a nitrogen source, slight differences in media reaction were observed with Chlorella vulgaris and the main observation in this reaction is to be almost neutral or neighbor to acidic reaction due to the normal algal growth pattern. A slightly same manner was observed with Spirulina platensis, where media reaction was shifted to be slightly alkaline. This result explained the growth failure of Spirulina under such replacement; however urea markedly reduced media reaction to acidic reaction. Nitrate nitrogen represented the same pattern of urea nitrogen with Chlorella algal growth, while Spirulina growth represented the completely alkaline reaction. In this connection (Wang et al., 
2010) found that urea buffers media reaction in neutral side due to the liberated carbon dioxide as algal growth was preceded.

\section{Effect of Nitrogen Sources on Salinity Margin:}

In this action, two growth media were used (BG-II and Zarrouk) with great gape between themselves on final nutrients concentration or their electric conductivity profile. The variation of such values at zero and end of incubation time monitored the degree of desalination or the rate of nutrients removed due to algal growth.

As shown in Fig.3, the nutrients initial concentration of BG-II for

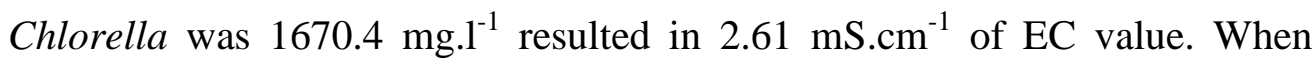
nitrate nitrogen was substituted by urea nitrogen, the initial nutrients concentration was lowered to be $704 \mathrm{mg} . \mathrm{l}^{-1}$ equal to $1.1 \mathrm{mS} . \mathrm{cm}^{-1}$ of EC value. At the first growth period, (48 hrs.) values of EC were drastically downed in both nitrogen source cultures, where the initial EC by such time was recorded as 1.0 and $0.4 \mathrm{mS} . \mathrm{cm}^{-1}$ with nitrate and urea nitrogen grown Chlorella cultures, respectively.
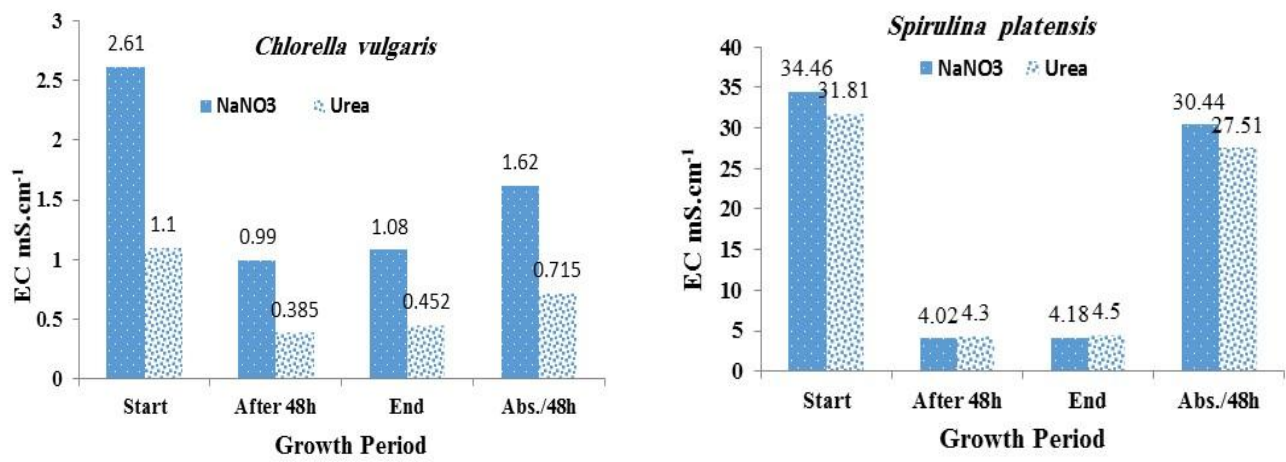

6 Fig. 2. Electrical conductivity profile of growth medium incubated with Chlorella vulgaris Beijerinck (NRC) and Spirulina platensis (Gomont) Geitler as affected by nitrogen source.

Start= value at zero time; after $48 \mathrm{~h}=$ value at maximum absorption ( $48 \mathrm{~h})$; End= value at the 
As growth was proceeded (14 days), both cultures (nitrate and urea) tended to possess a slight increase in E.C values $\left(1.1\right.$ and $0.5 \mathrm{mS} . \mathrm{cm}^{-1}$ with nitrate and urea nitrogen grown alga, respectively).

Data showed that the absorption rate seems to be more efficient with urea grown cultures $(65.0 \%)$ verses to nitrate $(62.07 \%)$. This result not only goes back to nitrate effect, but at first and as mentioned before return to the high initial concentration of nitrate media $\left(1677.4 \mathrm{mg} . \mathrm{l}^{-1}\right)$ as compared with urea media (704 mg. $\left.\mathrm{l}^{-1}\right)$. Data represented the maximum removing was performed within the early growth period (48hrs) and the slight increase observed at the late growth period.

In the case of Spirulina platensis the initial nutrients is very higher (10 fold approximately than BG-II), EC values of nitrate and urea cultures were found to be 34.5 and $31.81 \mathrm{mS} . \mathrm{cm}^{-1}$, respectively. After the define growth period (48hrs); nitrate grown cultures were superior urea grown cultures with a rate of consumption ( 88.33 and $86.48 \%$, respectively). At the end of incubation period consumption rate exhibited slight differences as compared with the early growth period or/and Chlorella case. This result could be attributed to death of algal cells, diffusion of cell sap during cell division or/and cell excretion as a biological function for nutrients absorption (ElSayed, 1999).

\section{Effect of Nitrogen Sources on Nutrient Removal: Nitrogen Removal:}

In the case of Chlorella vulgaris and as shown in Tables 1 and 2 , the maximum absorption rate were observed after 48 hour with urea nitrogen grown cultures (93.29\%) with absorption rate of $4.8 \mathrm{mg} . \mathrm{l}^{-1} \mathrm{~N} . \mathrm{h}^{-1}$ while, in 
nitrate nitrogen grown cultures $(91.17 \%)$ with absorption rate of $4.69 \mathrm{mg} . \mathrm{l}^{-1}$ N.h ${ }^{-1}$ were observed. During the whole growth period (14 days); a slight decrease was observed in urea grown cultures that reached $92.91 \%$, while nitrate grown cultures at the same period had no difference effect.

As for Spirulina platensis, nitrogen content of growth medium (Zarrouk) was folded than those of used for Chlorella vulgaris (BG-II) and Spirulina seems to be more efficient than Chlorella regarding nitrogen removal with nitrate nitrogen grown cultures that reached $92.16 \%$ with absorption rate of $7.91 \mathrm{mg} . \mathrm{l}^{-1} \mathrm{~N} . \mathrm{h}^{-1}$ after 48 hour, while decreased to $91.29 \%$ with urea nitrogen grown cultures and represented absorption rate $7.83 \mathrm{mg} . \mathrm{l}^{-1} \mathrm{~N} . \mathrm{h}^{-1}$.

During the whole growth period (14 days); no obvious differences were observed with Spirulina consumption rate. This result indicated that nitrogen consumption rate was source dependent, but its quantity varied due to initial or given concentration and grown algal species. The results revealed that beside the important physiological role of nitrogen in algae nutrition is also return to nitrogen source corresponding to algal strain and media concentration.

In this connection, Solomon and Gilbert (2008) reported that urea nitrogen source، is relatively cheaper than other nitrogen sources، and can also be easily utilized after being degraded to ammonium and bicarbonate via urease in most microalgae. Beuckels et al. (2015) showed the positive effect of nitrogen availability on the accumulation of phosphorus in microalgae cells. 


\section{Phosphorous Removal:}

As shown in Tables 1 and 2, urea Chlorella vulgaris grown cultures were superior nitrate grown cultures. Consumption percentages after the define growth period (48hrs); were found to be 85.14 and $59.71 \%$ and the rate of absorption was 0.12 and $0.09 \mathrm{mg} . \mathrm{l}^{-1} \mathrm{P} . \mathrm{h}^{-1}$, for urea and nitrate grown alga, respectively. At the end of the incubation period (14 days); the average of phosphorus consumption in urea grown cultures downed to $71.86 \%$, while there was no difference between early and late growth period in nitrate grown cultures. Urea nitrogen is expected to enhance phosphorous absorption by the green alga Chlorella vulgaris due to its effect on photosynthesis as an extra carbon source fed algal cells by its carbon skeleton (Norström et al., 2004). Dziosa and Makowska (2016) found that the increase in optical density of Chlorella sp. until the $8^{\text {th }}$ day of the culture was relatively low, but the microalgae assimilated the highest amount of phosphorous (about $74.8 \%$ of the initial phosphorus content in the culture medium). Its value increased three-fold (from 0.11 to 0.34 ).

In Spirulina platensis case, phosphorous absorption at the early growth phase (48hrs.) was higher than in nitrate grown cultures compared with urea which were 81.11 and $77.75 \%$ with the absorption rate of 1.5 and $1.44 \mathrm{mg} . \mathrm{l}^{-1}$ P. $\mathrm{h}^{-1}$, respectively. At the end of the incubation period (14 days), no differences in nitrate and urea grown cultures were observed. In this connection (El-Sayed et al., 2008) reported that comparing of both algae in concern phosphorous accumulation resulted in the high potential of Spirulina platensis to absorb phosphorus rather than Chlorella, however, Chlorella able to accumulate elevated amount of phosphorous. Dziosa and Makowska 
(2016) found that the influence of phosphorus on the growth of algae biomass certainly depends on the species, culture conditions, and other environmental parameters.

\section{Potasium Removal:}

As shown in Tables 1 and 2, potassium absorption at the early growth phase (48hrs.) by Chlorella vulgaris in urea nitrogen grown cultures was higher than in nitrate grown cultures which were 81.45 and $63.8 \%$ with the absorption rate of 0.3 and $0.24 \mathrm{mg} . \mathrm{l}^{-1} \mathrm{~K} \cdot \mathrm{h}^{-1}$, respectively. At the end of the incubation period (14 days), downed in the rate of consumption in both urea and nitrate occurred, which reached 60.89 and $55.36 \%$, respectively. This meaning that urea stimulates potassium consumption by enhancing algal growth through urea nitrogen nutrition at the early growth period, where $\mathrm{K}$ is required for carbohydrate metabolism.

In the case of Spirulina platensis urea consumption percentage of potassium at the early growth phase (48hrs.) was better than nitrate, which was found to be 96.72 and $94.49 \%$ with the absorption rate of 13.54 and $13.22 \mathrm{mg} . \mathrm{l}^{-1} \mathrm{~K} . \mathrm{h}^{-1}$, respectively. No differences in nitrate and urea grown culture were observed at the end of the incubation. This result is due to the reduction of sodium ions in urea culture, which led to absorption of potassium as an alternative to sodium by Spirulina platensis (Castro et al., 2015) .

In contrast, sodium could replaces potassium in algal nutrition and a wide range of algal categories able to grow and complete their life cycle within a hyper saline water poor in potassium parallel with high sodium ions including sea and lakes. In this action, urea might able to engage alga to accumulate $\mathrm{Na}$ 
ions. Moreover, potassium nutrition is closely related with nitrogen and phosphorous both in algae and higher plant nutrition. Increasing of potassium absorption by urea nitrogen might be explaining the low absorption rate of sodium under the same conditions, where algae and other plants prefer potassium.

Sodium Removal: Carbon, sodium and nitrogen represented the most important nutrients concerning algal growth media especially with brackish and marine algae. Even in the case of Chlorella that recommended to grow with BG-II growth medium; sodium as well as nitrogen were considered as essential growth elements.

In the case of Chlorella vulgaris sodium ions absorbed with nitrate was observed during the early growth phase (48 hrs.) as $61.05 \%$ resulted in 5.27 mg. $\mathrm{l}^{-1} \mathrm{Na} . \mathrm{h}^{-1}$; while the absorption during the whole incubation period was $60.2 \%$ resulting in $0.743 \mathrm{mg} . \mathrm{l}^{-1} \mathrm{Na}^{-1} \mathrm{~h}^{-1}$ Tables 1 and 2).

When urea replaced nitrate, a completely opposite manner was observed and the absorption rate was found to be very heights. Here, maximum absorption by the early period (48 hrs.) was found $89.51 \%$ resulting in 7.73 mg. $1^{-1} \mathrm{Na} \cdot \mathrm{h}^{-1}$. ; while the absorption during the whole incubation period was $87.70 \%$ resulting in $1.082 \mathrm{mg} . \mathrm{l}^{-1} \mathrm{Na} \cdot \mathrm{h}^{-1}$. This result indicated that sodium is required as regulator element in response to osmosis since sodium not included in cell structure beside the main function as potassium replacement in translocation and co-factor for certain enzymes

In the case of nitrate grown Spirulina platensis, a huge increase of sodium ion was given by its Zarrouk growth medium that serves as 5998.2 mg. $1^{-1} \mathrm{Na}$ comparing with $414.6 \mathrm{mg} . \mathrm{l}^{-1} \mathrm{Na}$ of original BG-II for Chlorella 
vulgaris. So, maximum absorption by the early growth period (48 hrs.) was found as $96.2 \%$ resulting in $120.21 \mathrm{mg} . \mathrm{l}^{-1} \mathrm{Na}^{-1}{ }^{-1}$; while $96.97 \%$ resulting in $17.31 \mathrm{mg} . \mathrm{l}^{-1} \mathrm{Na} . \mathrm{h}^{-1}$ was absorbed during the whole incubation period. When Spirulina platensis was incubated with urea nitrogen, decline in the rate of absorption by the early growth period (48 hrs.) was found as $84.01 \%$ resulting in $104.98 \mathrm{mg}^{-1} \mathrm{Na}^{-1}$; while the absorption during the whole incubation period was $83.85 \%$ resulting in $14.96 \mathrm{mg} . \mathrm{l}^{-1} \mathrm{Na} \cdot \mathrm{h}^{-1}$. Data indicated that Sodium ions which considered as the main salinity reason was found to be the most removable rate by Spirulina platensis in both growth medium (nitrate or urea-nitrogen).

Data revealed the enhancing effect of urea due to its effect on acceleration of some ions consumption like sodium. Furthermore, it could be noted that removing rate of nutrients was found to be functional and concentration dependent.

Calcium Removal: Beside calcium function in some cell enzymatic system, calcium was early considered as cell wall cement that illustrates the ability of most algal categories to grow well under classified habitats. Some algal cell able to accumulate a huge amount of calcium ions and defined as calcareous algae. Calcium concentration in most algal growth media was found to be more than other elements like phosphorous, sodium and potassium and calcium become more desired at the early growth phase, which represented the acceleration of algal cell division (Hepler, 2005).

As shown in Tables 1 and 2 under nitrate nitrogen, absorption percentage of calcium ions at early growth phase by Chlorella was $38.32 \%$ revealing that 
absorption rate by such time was $0.104 \mathrm{mg} \cdot \mathrm{l}^{-1} \mathrm{Ca}^{+2} \cdot \mathrm{h}^{-1}$. While, at the end of the incubation absorption percentage was downed to $30.61 \%$ resulting in $0.012 \mathrm{mg} . \mathrm{l}^{-1} \mathrm{Ca} . \mathrm{h}^{-1}$. When urea nitrogen was used, an extra stimulatory effect on calcium absorption was observed comparing with nitrate nitrogen grown Chlorella vulgaris both at early (48 hrs.) and later-growth period (14 days). Thus, $73.01 \%$ Ca was absorbed equal to $0.2 \mathrm{mg} . \mathrm{l}^{-1} \mathrm{Ca} \cdot \mathrm{h}^{-1}$, while at the end of the incubation absorption percentage was downed to $55.28 \%$ resulting in $0.021 \mathrm{mg} . \mathrm{l}^{-1} \mathrm{Ca} \cdot \mathrm{h}^{-1}$.

Spirulina platensis growth medium found to be rich in nutrients rather than Chlorella growth medium except calcium which represented the neighbor concentration (12.972 - $14.42 \mathrm{mg} . \mathrm{l}^{-1} \mathrm{Ca}^{+2}$ ). Nitrate grown Spirulina platensis possesses a higher $\mathrm{Ca}$ absorption percentage $37.59 \%$ equal to 0.113 mg. $1^{-1}$ Ca.h ${ }^{-1}$, compared with those grown under urea nitrogen $23.72 \%$ equal to $0.07 \mathrm{mg} . \mathrm{l}^{-1} \mathrm{Ca} \cdot \mathrm{h}^{-1}$. In both nitrogen sources, the net absorption rate during the whole cultivation period was ranged from $0.007 \mathrm{mg} \cdot \mathrm{l}^{-1} \mathrm{Ca} \cdot \mathrm{h}^{-1}$ in urea nitrogen to $0.015 \mathrm{mg} . \mathrm{l}^{-1} \mathrm{Ca}^{-1} \mathrm{~h}^{-1}$ with nitrate nitrogen. In conclusion and regardless nitrogen source, the percentage of calcium absorption by both algae was greatly varied. 
J. Environ. Sci.

Institute of Environmental Studies and Research - Ain Shams University

Table 1. Initial, maximum absorption and rate of nutrients absorption (mg. $\left.1^{-1}\right)$ by nitrate grown Chlorella vulgaris and Spirulina platensis

\begin{tabular}{|c|c|c|c|c|c|c|c|}
\hline \multirow{2}{*}{ Nu. } & Alga & Init. & $\begin{array}{c}\text { Abs. } \\
\text { Rate } \\
\text { h1/48h }\end{array}$ & $\begin{array}{c}\text { Abs. } \\
\text { Rate\% } \\
\mathbf{4 8 h}\end{array}$ & $\begin{array}{c}\text { Ele. } \\
\text { Conc. } \\
\text { End }\end{array}$ & $\begin{array}{c}\text { Abs. } \\
\text { Rate } \\
\text { h2/14d }\end{array}$ & $\begin{array}{c}\text { Abs. } \\
\text { Rate\% 14d }\end{array}$ \\
\hline \hline \multirow{2}{*}{$\mathbf{N}$} & $\boldsymbol{C h}$. & 247 & 4.69 & 91.17 & 21.00 & 0.673 & 91.50 \\
\cline { 2 - 8 } & $\boldsymbol{S p}$. & 411.8 & 7.91 & 92.16 & 34.50 & 1.12 & 91.62 \\
\hline \multirow{2}{*}{$\mathbf{P}$} & $\boldsymbol{C h}$. & 7.00 & 0.09 & 59.71 & 3.01 & 0.012 & 57.00 \\
\cline { 2 - 8 } & $\boldsymbol{S p}$. & 88.9 & 1.50 & 81.11 & 18.02 & 0.211 & 79.73 \\
\hline \multirow{2}{*}{ K } & $\boldsymbol{C h}$. & 17.9 & 0.24 & 63.80 & 7.99 & 0.029 & 55.36 \\
\cline { 2 - 8 } & $\mathbf{S p .}$ & 671.7 & 13.22 & 94.49 & 22.48 & 1.932 & 96.65 \\
\hline \multirow{2}{*}{ Na } & $\boldsymbol{C h}$. & 414.6 & 5.27 & 61.05 & 165.0 & 0.743 & 60.20 \\
\cline { 2 - 8 } & $\boldsymbol{S p}$. & 5998.2 & 120.2 & 96.20 & 181.5 & 17.31 & 96.97 \\
\hline \multirow{2}{*}{ Ca } & $\mathbf{C h .}$ & 12.97 & 0.104 & 38.32 & 9.00 & 0.012 & 30.61 \\
\cline { 2 - 8 } & Sp. & 14.42 & 0.113 & 37.59 & 9.50 & 0.015 & 34.12 \\
\hline
\end{tabular}

Init. Ele. Conc. $=$ initial element concentration at zero time, Abs. Rate ${ }_{\mathrm{h} 1 / 48 \mathrm{~h}}=$ Rate of absorption per hour during ${ }_{48}$ hours of incubation, $\mathrm{Nu}$. Conc. 14 days $=$ initial element concentration at the end of incubation, Abs. Rate ${ }_{\mathrm{h} 2 / 14 \mathrm{~d}}=$ Rate of absorption per hour during the whole incubation period, Abs. $\%=$ Rate of absorption percentage, $\mathrm{Ch} .=$ Chlorella vulgaris Beijerinck (NRC) ,Sp.= Spirulina platensis (Gomont) Geitler 
Table 2. Initial, maximum absorption and rate of nutrients absorption (mg. $\mathrm{l}^{-1}$ ) by urea grown Chlorella vulgaris and Spirulina platensis

\begin{tabular}{|c|c|c|c|c|c|c|c|}
\hline \multirow{2}{*}{ Nu. } & Alga & Init. & $\begin{array}{c}\text { Abs. } \\
\text { Rate } \\
\text { h1/48h }\end{array}$ & $\begin{array}{c}\text { Abs. } \\
\text { Rate\% } \\
\mathbf{4 8 h}\end{array}$ & $\begin{array}{c}\text { Ele. } \\
\text { Conc. } \\
\text { End }\end{array}$ & $\begin{array}{c}\text { Abs. } \\
\text { Rate } \\
\mathbf{h 2 / 1 4 d}\end{array}$ & $\begin{array}{c}\text { Abs. } \\
\text { Rate\% 14d }\end{array}$ \\
\hline \multirow{2}{*}{$\mathbf{N}$} & Ch. & 247 & 4.80 & 93.29 & 19.30 & 0.678 & 92.19 \\
\cline { 2 - 8 } & $S p$. & 411.8 & 7.83 & 91.29 & 38.29 & 1.112 & 90.70 \\
\hline \multirow{2}{*}{$\mathbf{P}$} & Ch. & 7.00 & 0.12 & 85.14 & 1.97 & 0.015 & 71.86 \\
\cline { 2 - 8 } & $S p$. & 88.9 & 1.44 & 77.75 & 20.45 & 0.204 & 77.00 \\
\hline \multirow{2}{*}{ K } & Ch. & 17.9 & 0.30 & 81.45 & 7.00 & 0.032 & 60.89 \\
\cline { 2 - 8 } & Sp. & 671.7 & 13.54 & 96.72 & 26.00 & 1.922 & 96.13 \\
\hline \multirow{2}{*}{ Na } & Ch. & 414.6 & 7.73 & 89.51 & 51.00 & 1.082 & 87.70 \\
\cline { 2 - 8 } & $S p$. & 5998.2 & 104.9 & 84.01 & 969.0 & 14.97 & 83.85 \\
\hline \multirow{2}{*}{ Ca } & Ch. & 12.97 & 0.20 & 73.01 & 5.80 & 0.021 & 55.28 \\
\cline { 2 - 8 } & Sp. & 14.42 & 0.07 & 23.72 & 12.00 & 0.007 & 16.78 \\
\hline \hline
\end{tabular}

Init. Ele. Conc. $=$ initial element concentration at zero time, Abs. Rate ${ }_{\mathrm{h} 1 / 48 \mathrm{~h}}=$ Rate of absorption per hour during ${ }_{48}$ hours of incubation, $\mathrm{Nu}$. Conc. 14 days $=$ initial element concentration at the end of incubation, Abs. Rate ${ }_{\mathrm{h} 2 / 14 \mathrm{~d}}=$ Rate of absorption per hour during the whole incubation period, Abs. $\%=$ Rate of absorption percentage, Ch.= Chlorella vulgaris Beijerinck (NRC) ,Sp.= Spirulina platensis (Gomont) Geitler

\section{CONCLUSION}

Most algae species prefer nitrate nitrogen, which increases most of growth parameters. Ammonical nitrogen of urea addition seems to be more preferred in algal mass production due to its low price and its initial carbon content. In addition, urea stimulates nutrients removal due to its acidic reaction effect of growth medium.

\section{ACKNOWLEDGMENT}

This research work has been carried out as a part of activities of Algal Biotechnology Unit, National Research Centre, Dokki, Cairo, Egypt, (Prof. 
Dr. Abo El-Khair B. El-Sayed). The authors express thanks to all other stuff members.

\section{REFERENCES}

Battah, M. G.; El-Sayed, A.B. and El-Sayed, E.W. (2013). Growth of the green alga Chlorella vulgaris as affected by different carbon sources. Life Science Journal; 10(1):2075-2081.

Bernet, N and Beline, F. (2009) Challenges and innovations on biological treatment of livestock effluents. Biores Tech 100:5431-5436

Beuckels A., Smolders E., Muylaert K.(2015). Nitrogen avalability influences phosphorus removalin microalgae-based wastewater treatment. Water research, 77, 98-106

Blier, R., Laliberte, G. and De la Nou"e, J., (1995). Tertiary treatment of cheese factory anaerobic effluent with Phormidium bohneri and Micractinium pusillum. Bioresour. Technol.; 52, 151-155.

Burton, C. H. (2007). The potential contribution of separation technologies to the management of livestock manure. Livestock Science, 112(3), 208-216.

Burton C. H. and Turner C. (2003). Manure Management: Treatment Strategies for Sustainable Agriculture. Silsoe Research Institute. 2nd ed. Wrest Park, Silsoe, Bedford, UK.

Cai, T., Park, S. Y. \& Li, Y. (2013). Nutrient recovery from wastewater Streams by microalgae: status and prospects. Renew. Sustain. Energy Rev. 19:360-369.

Castro, G.P.F.S.; Rizzd, R.F. and Passds, T.S. (2015). Biomass production by Arthrospira platensis under different culture conditions. Food Science and Technology. 35(1): 18-24.

Chpman, H.D. and Pratt, P.F. (1974). Methods for Soils, Plants and Waters Agricultural Division Sciences, California Univ., Berkeley, USA. 
Dalrymple, O. K.; Halfhide, T.; Udom I.; Gilles, B.; Wolan, J., Zhang, Q, and Ergas S. (2013). Generation of Renewable Resources: a Review and Preliminary Results. Aquatic Biosystems, 9(2).

Dziosa, K., Makowska, M. (2016). Monitoring of chlorella sp. growth based on the optical density measurement. Institute for Sustainable Technologies - National Research Institute, Radom, 2, 197- 206.

El-Sayed, A. B.; Abdel-Maguid, A. A. and Hoballah, E.M. (2011). Growth response of Chlorella vulgaris to acetate carbon and nitrogen forms. Nature and Science, 9(9): 53-58.

El-Sayed, A.B. (2007). Economizing of intensive outdoor mass production of the green alga Scenedesmus sp. Egyptian J. of Phycology, 8, 8596.

El-Sayed, A.B. (1999). Some physiological studies on green algae. Ph.D. Thesis, Faculty of Agric., Department of Agriculture Botany, Cairo University.

El-Sayed, A.B.; Abdalla, F. E. and Abdel-Maguid, A. A. (2001). Use of Some Commercial Fertilizer Compounds for Scenedesmus Cultivation. Egyptian J. Phycology, 2, 9-16.

El-Sayed, A.B.; Battah M. G. and El-Sayed, E.W. (2015). Utilization efficiency of artificial carbon dioxide and corn steam liquor by Chlorella vulgaris. Biolife, 3(2):391-403.

El-Sayed, A.B.; Hoballah, E.M. and Khalafallah, M.A. (2012) Utilization of Citrate Wastes by Scenedesmus sp. I- Enhancement of Vegetative Growth. Journal of Applied Sciences Research, 8(2): 739-745.

El-Sayed, A.B; El-Fouly, M.M. and El-Sayed, A.A. (2008). Utilization efficiency of elevated nitrogen, phosphorous and potassium concentrations by the green alga Scenedesmus sp. The 17th International Symposium of CIEC "Plant Nutrient Managment under Stress Conditions". NRC, Cairo, 2008. El-Sayed, 1999.

Hepler,P.K.(2005). Calcium: A Central Regulator of Plant Growth and Development. The Plant Cell, 17, 2142-2155.

Imbeah, M. (1998). Composting piggery waste: a review. Bioresour. Technol. 63, 197-203. 
Kalla, N. and Khan, S. (2016). Effect of nitrogen, phosphorus concentrations, $\mathrm{pH}$ and salinity ranges on growth, biomass and lipid accumulation of Chlorella vulgaris. Int. J. of Pharm. Sci. and Res.7 (1): 397 405.

Mitchell, S. and Richmond, A. (1988). Optimisation of a growth medium for Spirulina based on cattle waste. Biol. Waste, 25, 41-50.

Norström, A., Larsdotter, K., Gumaelius, L., la Cour Jansen, J. and Dalhammar, G. (2004). A small scale hydroponics wastewater treatment system under Swedish conditions. Wat. Sci. Technol. 48(11-12): 161-167.

Solomon, C. M. and Glibert, P. M. (2008). Urease activity in five phytoplankton species. Aquat. Microb. Ecol. 52:149-157.

Stainer. R.Y.; Kunisawa, R.; Mandel, M. and Cohin-Bazire, G. (1971) Purification and properties of unicellular blue-green algae (order Chrococcales). Bacteriol Rev.35:171-205.

Wang, L., Min, M., Li, Y., Chen, P., Chen, Y., Liu, Y., Wang, Y., Ruan, R., (2010). Cultivation of green algae Chlorella sp. in different wastewaters from municipal wastewater treatment plant. Applied Biochemistry and Biotechnology 162 (4), 1174-1186.

Wang, J., Sommerfeld, M. R., Lu, C. \& Hu, Q. (2013). Combined effect of initial biomass density and nitrogen concentration on growth and astaxanthin production of Haema tococcus pluvialis (Chlorophyta) in outdoor cultivation. Algae 28:193-202.

Zarrouk, C. (1966). Contribution à l'étude d'une cyanophycée. Influence de divers facteurs physiques et chimiques sur la croissance et photosynthese de Spirulina maxima Geitler Ph.D. Thesis, University of Paris. 


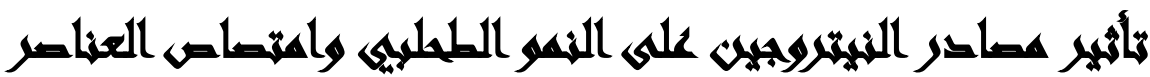

\section{[r]}

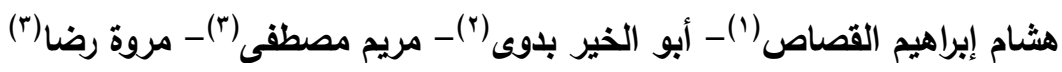

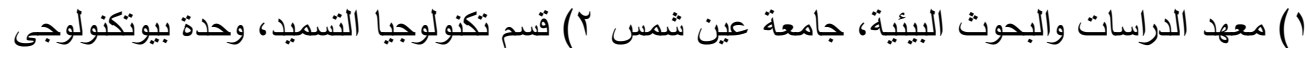

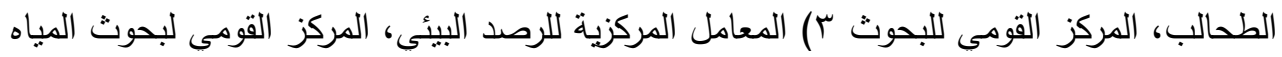

\section{المستخليص}

تم تتفيذ العمل الحالي بهدف تحديد خط نمو نوعين مختلفين من الطحالب تحت مصدرين من

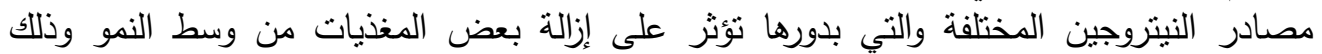

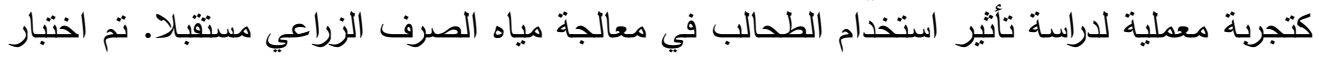

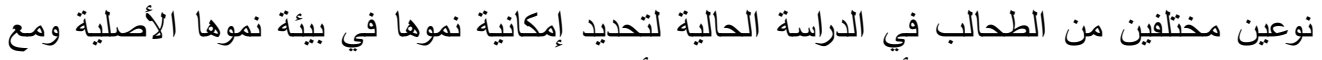

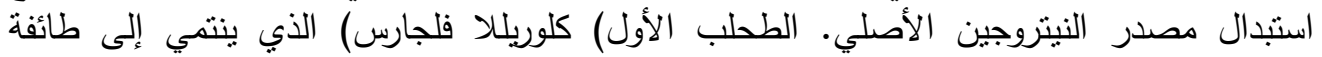

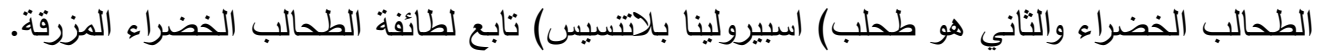

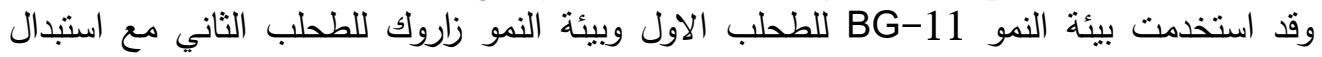

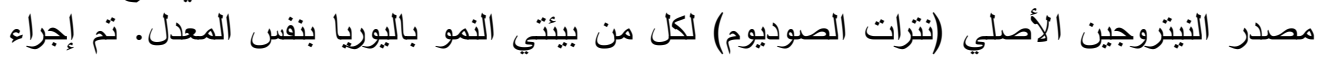
تقدير يومي للكتلة الحيوية ومعدل إستهلالك المغنيات.

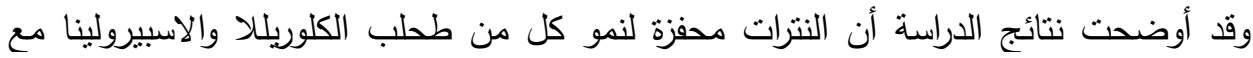

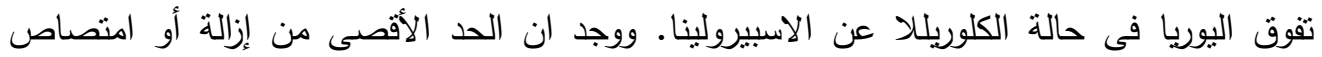

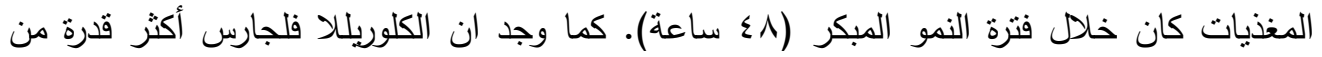

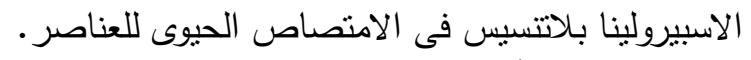

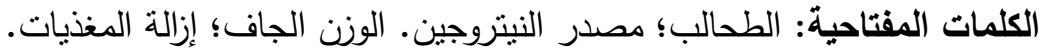

